\title{
Female sex workers living with HIV in Tanzania have both a need for contraception and a desire to have children in the future
}

Project SOAR

Follow this and additional works at: https://knowledgecommons.popcouncil.org/departments_sbsr-hiv

Part of the Demography, Population, and Ecology Commons, Family, Life Course, and Society Commons, International Public Health Commons, and the Women's Health Commons How does access to this work benefit you? Let us know!

\section{Recommended Citation}

Project SOAR. 2018. "Female sex workers living with HIV in Tanzania have both a need for contraception and a desire to have children in the future," Project SOAR Results Brief. Washington, DC: Population Council. 


\section{Health services should help women meet both needs}

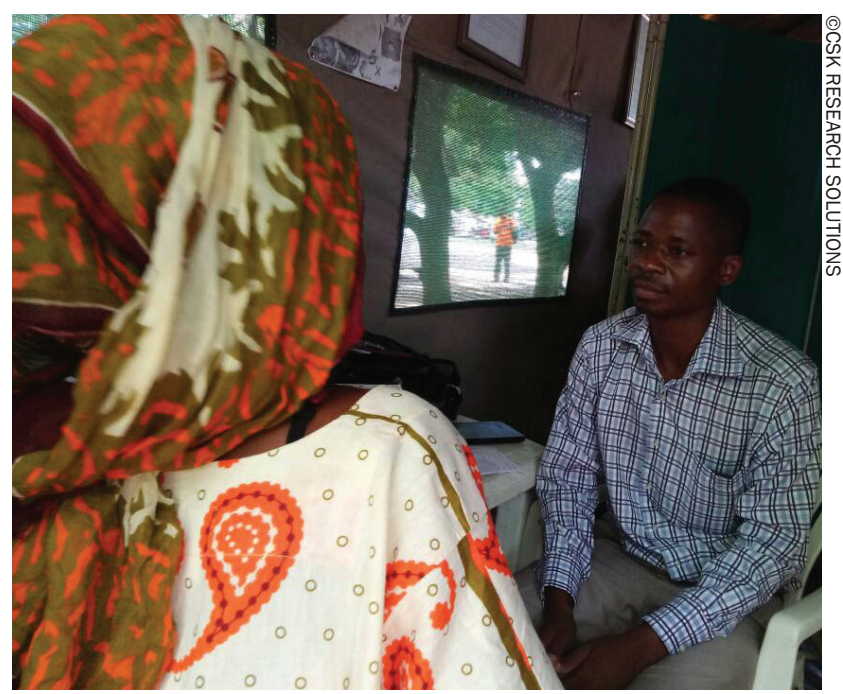

There is limited data on female sex workers need for contraception and desire to have children.

HIV-positive women often have critical family planning (FP) needs in addition to HIV-related care, treatment, and prevention concerns. In sub-Saharan Africa, unintended pregnancy is common among HIV-positive women. At the same time, many women living with HIV want to have children some day, and there are various "safer conception" strategies available to help HIV-affected individuals and couples get pregnant while minimizing the risk of HIV transmission to seronegative partners and the baby. Such strategies include, for example, timed unprotected intercourse (limited to the periovulatory period), self-insemination with sperm from an HIVnegative partner, pre-exposure prophylaxis (PrEP) for the HIV-negative partner, and antiretroviral therapy for the HIV-positive partner.

In Tanzania, national guidelines recommend providing FP and "safer pregnancy" counseling to women living with HIV, as well as integrated reproductive health services for female sex workers. However, there is no guidance on how to provide these holistic services. Moreover, there is limited data on these women's need for contraceptives and desire to have children to inform such guidance, which is important for reducing HIV transmission, and helping women decide whether and when to have children.

\section{OUR RESEARCH}

We asked 604 HIV-positive female sex workers about their fertility-related needs and desires. The women were ages 18 to 49 in Njombe and Mbeya provinces. ${ }^{1}$

\section{Study participants}
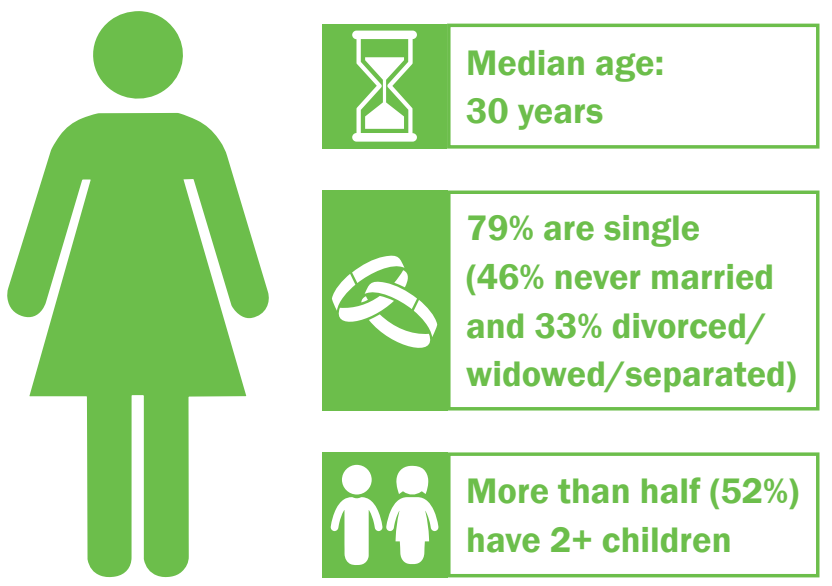

\section{WHAT DID WE LEARN?}

Our analysis indicates that most women want to prevent pregnancy, but there also is a notable minority interested in having children imminently or in the future. They have a critical need for both effective contraception as well as information about how to get pregnant while minimizing the risk of HIV transmission to partners and infants.

${ }^{1}$ These findings are based on a secondary analysis of data collected in a larger study that assesses a community-based approach to providing antiretroviral therapy for HIV-positive female sex workers in Tanzania. For more information about that study, visit projsoar.org/ our-activities/tanzania-fsw-hiv-treatment.
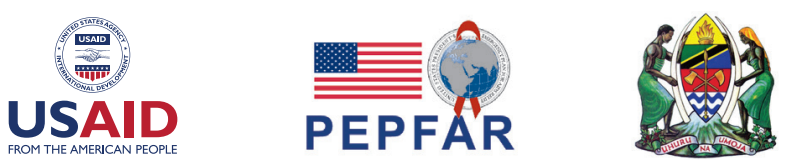

POPULATION COUNCIL

Ideas. Evidence. Impact.

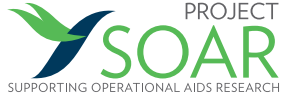




\section{KEY FINDINGS}

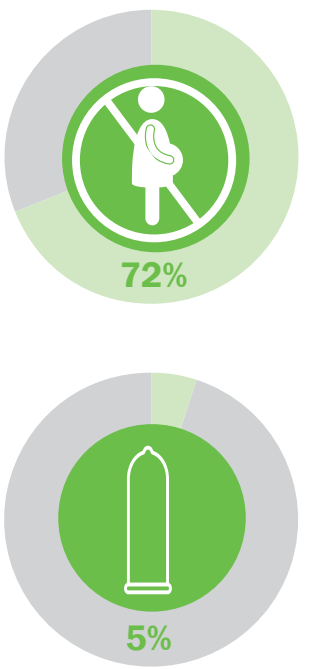

More than 2/3 of women don't want to get pregnant in the next 2 years.

Just 5\% report using

condoms consistently. *

Using a modern method other

than condoms is common among these women

(69\%).

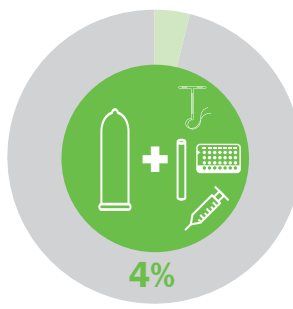

A very small minority (4\%) report dual protection: consistent condom use* as well as use of an effective non-barrier method to protect against pregnancy and HIV/STIs.

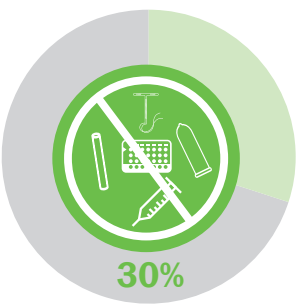

But 30\% have an unmet need for contraception. These women do not want to get pregnant in the next two years, but are neither consistent condom users nor users of an effective non-barrier method.

*Consistent condom use is defined as "always" using condoms with paying clients in the past month, as well as with their most recent non-paying partner at last sex.

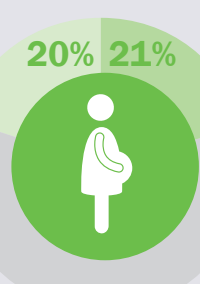

\section{Yet, many women have a} desire to have children.

$21 \%$ are currently trying to get pregnant and another $20 \%$ want to have a/nother child someday.

Among all participants, few women know of the following strategies to get pregnant more safely:

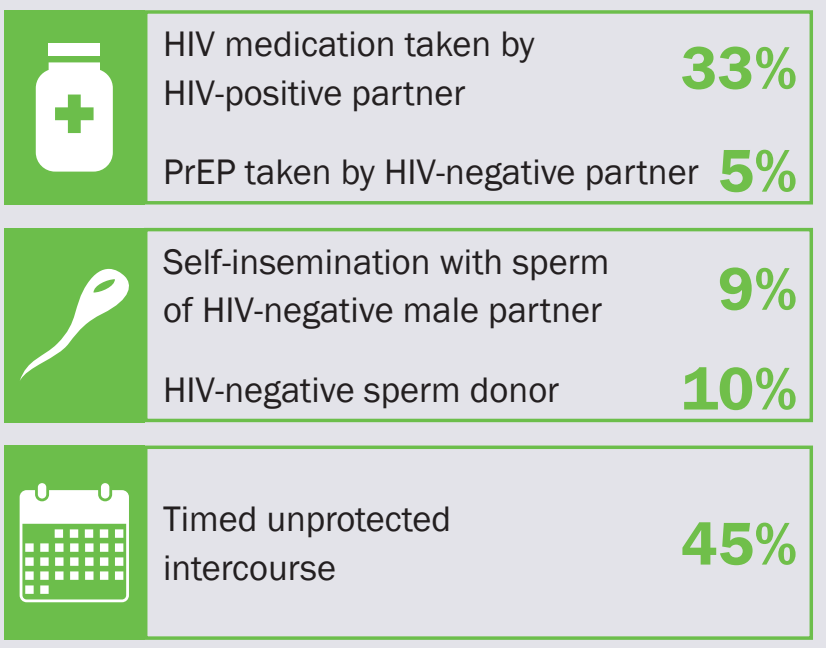

\begin{tabular}{|l} 
said they are "very interested" \\
$4.3 \%$ \\
in learning about how HIV- \\
positive women can get \\
pregnant more safely.
\end{tabular}

\section{EVIDENCE TO ACTION}

Services for women living with HIV should meet the contraceptive needs of those who wish to prevent pregnancy, as well as provide information on options to get pregnant more safely for those who plan to have children. Such integrated services are needed to reduce the risk of unintended pregnancy as well as vertical and sexual HIV transmission among HIVpositive women of reproductive age.

Suggested citation: Project SOAR. 2018. "Female sex workers living with HIV in Tanzania have both a need for contraception and a desire to have children in the future," Project SOAR Results Brief. Washington, DC: Population Council.
Project SOAR is a five-year (September 2014-September 2019) cooperative agreement funded by the President's Emergency Plan for AIDS Relief and the U. S. Agency for International Development (Agreement No. AIDOAA-A-14-00060). SOAR is able to accept funding from all USAID accounts.

Population Council leads the Project SOAR consortium in collaboration with Avenir Health, Elizabeth Glaser Pediatric AIDS Foundation, the Johns Hopkins University, Palladium, and The University of North Carolina at Chapel Hill.
Project SOAR/Population Council

4301 Connecticut Avenue, NW, Suite 280

Washington, DC 20008

Tel: +1 2022379400

e-mail: ProjectSOAR@popcouncil.org

projsoar.org

(C) Population Council, April 2018 